OPEN ACCESS

Edited by:

Aida Turrini,

Independent Researcher, Rome, Italy

Reviewed by:

Hatem Mohamed,

Najran University, Saudi Arabia

Nik Shanita Safii,

Universiti Kebangsaan

Malaysia, Malaysia

*Correspondence:

Walaa Abdullah Mumena

wmumena@taibahu.edu.sa

Specialty section: This article was submitted to

Nutrition Methodology,

a section of the journa

Frontiers in Nutrition

Received: 16 July 2021 Accepted: 20 December 2021 Published: 04 February 2022

Citation:

Mumena WA and Kutbi HA (2022) Development of a Food Frequency Questionnaire for Assessing Habitual Intake of Free Sugar Among Children in Saudi Arabia. Front. Nutr. 8:742737.

doi: 10.3389/fnut.2021.742737

\section{Development of a Food Frequency Questionnaire for Assessing Habitual Intake of Free Sugar Among Children in Saudi Arabia}

\author{
Walaa Abdullah Mumena ${ }^{1 *}$ and Hebah Alawi Kutbi ${ }^{2}$ \\ ${ }^{1}$ Clinical Nutrition Department, College of Applied Medical Sciences, Taibah University, Madinah, Saudi Arabia, ${ }^{2}$ Clinical \\ Nutrition Department, Faculty of Applied Medical Sciences, King Abdulaziz University, Jeddah, Saudi Arabia
}

The World Health Organization emphasizes the urgency to assess and limit the intake of free sugar (FS) among individuals in order to prevent several non-communicable diseases. However, data regarding intake of FS are lacking in Saudi Arabia and in the Middle East. A reliable valid tool is needed to assess children's habitual intake of FS. Thus, we aimed to develop and validate a food frequency questionnaire (FFQ) that assesses children's habitual intake of FS in Saudi Arabia. In this cross-sectional study, 424 healthy Saudi children ages 6-12 years were included using river sampling method. Sociodemographic data and contact information were collected from mothers using an online survey. Dietary data were collected using 24-h dietary recalls (reference method) and a semi-quantitative FFQ through phone interviews. Items and food groups included in the initial draft of the FFQ were adopted from previous work. Content validity was done to the FFQ with total of 12 food groups and 41 food items. Next, a pilot study was conducted to estimate the sample size needed for the study and to ensure that all items reported in the 24-h dietary recalls were included in the final draft of the FFQ. Finally, data were collected to assess the validity and reliability of the FFQ at the population level. Mean intake of FS assessed by the FFQ was significantly higher than that assessed by the 24-h dietary recalls. Spearman's correlation between total FS assessed by the FFQ and 24-h dietary recall was positively low $\left(r_{\mathrm{S}}=0.30, p<0.001\right)$. The coefficient alpha indicated an acceptable level of internal consistency $(\alpha=0.74, p<0.001)$. Test-retest reliability for total FS intake assessed by the FFQ was positively high $\left(r_{s}=0.82\right)$. A slight agreement between FS intake assessed by the FFQ and the 24-h dietary recall was seen among the study sample $(\kappa=0.21, p<0.001$ ). The newly developed FFQ was found to be reasonably valid in assessing children's habitual intake of FS in Saudi Arabia. Validating the instrument among older population in Saudi Arabia is warranted.

Keywords: food frequency questionnaire, free sugar intake, validation, children, Saudi Arabia 


\section{INTRODUCTION}

The global increase in non-communicable disease epidemics and the documented association with excessive free sugar (FS) consumption had led many countries to establish fiscal policy interventions to limit intake of sugary foods, and it became a global health agenda $(1,2)$. The impact of excessive free/added sugar intake on health was supported by abundant studies that linked high sugar consumption with overweight (3), dental caries (4), poor dietary quality/intake (5-7), cardiovascular diseases (8), and mortality (9). As an effort to reduce FS consumption among the population, the World Health Organization (WHO) has developed evidence-based guidelines that may further assist policymakers and community programs to reach this goal (10).

The term "free sugar" is used to describe mono- and disaccharides that are naturally present in syrups, honey, and fruit juices, and sugars added to food by consumers or manufacturers, whereas "added sugar" does not include sugar occurring naturally in foods $(11,12)$. Despite the inconsistences in defining added sugar and FS in research and food labeling, recent recommendations developed by health organizations favors an emphasis on FS due to its impact on health (11). The WHO recommendations include limiting FS intake to $<10 \%$ and more recently $<5 \%$ of total energy intake (or $<25$ grams of FS per day) to prevent excess body weight and tooth decay and to promote overall health (10). This recommendation has been followed by the Saudi Ministry of Health (13). To promote dietary patterns fitting these recommendation, the first step is to assess and monitor FS intake among the populations (10). Assessment of FS intake requires the availability of a validated tool that can be applied in epidemiological studies. Previous studies that attempted to evaluate consumption of FS in Saudi Arabia focused only on certain food items, e.g., sugar sweetened beverages or candies (14-16). Data obtained from such tools cannot provide data regarding total amount of free sugar.

Limiting FS intake among children has been a priority for many intervention programs given that children are one of the most vulnerable groups for excessive sugar intake (17). Another area of concern is that dietary behaviors in childhood may persist into adulthood (18). As such, intervention studies have been devoted to investigate how to promote healthy food choices and dietary habits and limit FS intake effectively among children (1921). In Saudi Arabia and the Middle East, data regarding intake of FS are lacking. A reliable valid tool is needed to assess children's habitual intake of FS in the region. Thus, the present study aimed to develop a validate a culture-specific food frequency questionnaire (FFQ) to assist in estimating the habitual FS intake among Saudi children.

\section{MATERIALS AND METHODS Study Design and Population}

Saudi healthy children ages 6-12 years were included in this cross-sectional study. Children with food allergy or any chronic disease, siblings of a child whose data were already collected, and children who reside outside of Saudi Arabia were excluded. A pilot sample of 36 children and their mothers was recruited to determine the sample size needed for the present study. Based on the correlation between FS intake from the 24-h dietary recall and from the FFQ $(r=0.31)$, a minimum of 85 children was needed with alpha $=0.05$ and power of $80 \%$ (22). Ethical clearance to conduct this study was obtained from the ethical committee of the College of Applied Medical Sciences, Taibah University (certificate\# 2020/55/202/CLN). Consent form was obtained via the online survey from all mothers before collecting children's data.

\section{Data Collection}

Mothers of children were recruited using river sampling, wherein an online survey was distributed via multiple social media channels, such as WhatsApp, Twitter, and Facebook to collect sociodemographic data (child's age and sex, maternal age and education level, and family income). The online survey was distributed for a duration of 3 months then the data collection was stopped. A text message was sent to all mothers who provided consent for their children to be part of the study to arrange for a phone interview for dietary data collection. The phone interview was conducted by trained dietetic professionals with mothers to collect the dietary data with the presence of the child and the person responsible for child's eating. Dietary data were assessed by 24 -h dietary recalls and a semi-quantitative FFQ. During the phone-administered interview, the FFQ was collected followed by the 24-h dietary recall. All mothers received the portion size guide to help them estimate the portion size of foods consumed. The portion size guide included pictures of standardized serving sizes of all food groups (grains, fruits, vegetables, milk and dairy products, meats and alternatives). Pictures of standardized portion sizes of drinks, candies, and sweets were also included in the portion size guide.

\section{4-h Dietary Recalls}

The 24-h dietary recall was used as a reference method to assess the intake of FS. Single 24-h dietary recall from all children was collected; two additional 24-h dietary recalls (for non-consecutive days) were collected from a subsample of 165 children (38.9\%) to adjust for within-person variation. Mothers were requested to remember and report the food intake of children during the past 24 hours. The data obtained from the 24-h dietary recalls were recorded on paper then entered into the Nutritics software https://www.nutritics.com/p/references (version 5.09, Dublin, Ireland) (data source: Nutritics: Middle East/Arabic-Arabic foods/popular Gulf recipes). The Nutritics software provides data concerning content of FS specifically in addition to total sugar and several other nutrients (macro and micronutrients). When amount of FS was not specified for a local food, quantities of FS were estimated based on standardized recipes that were created in the software. The primary investigators trained the data collection team, validated the ingredients of all recipes before inserting them into the software, and monitored the data collection to ensure quality of the data collected. The dietary data were later imported into an Excel sheet in order to calculate the average of the 3 days obtained 
from the subsample and to prepare the dietary data of all children to be analyzed.

\section{Development and Validation of the FFQ}

The semi-quantitative FFQ was developed to assess the habitual intake of FS. Items of the FFQ were initially adapted from a study that identified the top food sources of added sugar among American children, of which included 17 food groups and 78 food items (17). Content validity was conducted by four experts in the field who provided insight into the FFQ based on diet of the population in Saudi Arabia. Items that are not consumed frequently by Saudis and items that contain low amounts of FS $(<5 \mathrm{~g}$ of FS in $100 \mathrm{~g})$ were eliminated, including grain drinks, processed meats, and fats/oils. Food items that contain high quantities of FS and were frequently consumed in Saudi Arabia, including chocolate spread, peanut butter, cheesecake, and salad dressings were added into the FFQ. Further, food items that contain FS but were not included in the original FFQ were added to the newly developed FFQ. Similar to the approach used by a Malaysian study to validate a semi-quantitative FFQ (23), we estimated the quantity of FS for each food item included in the FFQ based on standardized portion size to obtain semi-quantitative data. The newly developed semi-quantitative FFQ calculates the quantity of FS from liquid and solid food sources separately as well as the total content of FS (see Table 1). Estimated quantity of FS in each food item was determined using Nutritics software. Portion sizes used in the FFQ were specified based on the standard/mostly used portion sizes of products available in the Saudi market.

Next, a pilot sample of 36 children were recruited to ensure that all FS-containing food items reported in the 24-h dietary recalls were listed in the newly developed FFQ. Accordingly, a total of 12 food groups and 41 food items divided into liquid food sources and solid food sources of FS were included in the final version of the FFQ.

The final version of the semi-quantitative FFQ has been later utilized to collect data of children for the present study. During the phone-administered interview, the FFQ was collected followed by the 24-h dietary recall. Firstly, mothers received the portion size guide to help them estimate the portion size of items included in the FFQ. Additionally, a table that includes the frequency response options of the FFQ has been sent to the mothers to ensure accuracy of reporting through showing the response options as follows: per day (once, 2-3 times, 4-5 times, or 6 times or more), per week (once, 2-4 times, or 56 times), per month (<once or 1-3 times). Responses to FFQ for each child were recorded on a printed copy of the FFQ then entered into an Excel sheet that calculates the FS content. A separate Excel sheet was used for each child to calculate the total FS intake; the total intake was then inserted in the main Excel sheet that include data for all children. To assess test-retest reliability of the FFQ, data were collected one more time for a subsample of 55 children (13.0\%) within 1 month of collecting the first FFQ.
TABLE 1 | Food groups, food items, and standard portion size included in the FFQ used to assess the habitual intake of free sugar among Saudi children.

\begin{tabular}{|c|c|c|c|}
\hline & Food group & Food items & $\begin{array}{c}\text { Standard port } \\
\text { size }\end{array}$ \\
\hline \multicolumn{4}{|c|}{ Liquid food sources of free sugar } \\
\hline \multirow[t]{5}{*}{1} & Sweetened & Fruit drink & $180 \mathrm{ml}$ \\
\hline & beverages & Soft drink & $330 \mathrm{ml}$ \\
\hline & & Energy drink & $250 \mathrm{ml}$ \\
\hline & & Flavored milk & $180 \mathrm{ml}$ \\
\hline & & Smoothie & $200 \mathrm{ml}$ \\
\hline \multicolumn{4}{|c|}{ Solid food sources of free sugar } \\
\hline \multirow[t]{2}{*}{2} & $\begin{array}{l}\text { Ready to eat } \\
\text { cereals }\end{array}$ & $\begin{array}{l}\text { Ready to eat cereals: lower } \\
\text { sugar }(\leq 21.2 \mathrm{~g} / 100 \mathrm{~g})\end{array}$ & $30 \mathrm{~g}$ \\
\hline & & $\begin{array}{l}\text { Ready to eat cereals: higher } \\
\text { sugar }(>21.2 \mathrm{~g} / 100 \mathrm{~g})\end{array}$ & $30 \mathrm{~g}$ \\
\hline \multirow[t]{2}{*}{3} & Breads and rolls & Yeast breads & $35 \mathrm{~g}$ \\
\hline & & Rolls and buns & $35 \mathrm{~g}$ \\
\hline \multirow[t]{10}{*}{4} & Sweet bakery & Cake & $30 \mathrm{~g}$ \\
\hline & products & Fruit pie or cheesecake & $30 \mathrm{~g}$ \\
\hline & & Cookies & $30 \mathrm{~g}$ \\
\hline & & Brownies & $30 \mathrm{~g}$ \\
\hline & & Doughnuts & $30 \mathrm{~g}$ \\
\hline & & Biscuit & $30 \mathrm{~g}$ \\
\hline & & Muffins & $30 \mathrm{~g}$ \\
\hline & & French toast & $30 \mathrm{~g}$ \\
\hline & & Pancakes/waffles & $30 \mathrm{~g}$ \\
\hline & & Sweet pastries & $30 \mathrm{~g}$ \\
\hline \multirow[t]{2}{*}{5} & Quick breads and & Croissant & $30 \mathrm{~g}$ \\
\hline & bread products & Pastries & $30 \mathrm{~g}$ \\
\hline \multirow[t]{2}{*}{6} & Candy & Candy containing chocolate & $30 \mathrm{~g}$ \\
\hline & & $\begin{array}{l}\text { Candy not containing } \\
\text { chocolate }\end{array}$ & $15 \mathrm{~g}$ \\
\hline \multirow[t]{4}{*}{7} & Other desserts & Ice-cream & $125 \mathrm{~g}$ \\
\hline & & Popsicle & $125 \mathrm{~g}$ \\
\hline & & Gelatin & $125 \mathrm{~g}$ \\
\hline & & Pudding & $125 \mathrm{~g}$ \\
\hline \multirow[t]{6}{*}{8} & Sugars & Sugars in tea and coffee & $15 \mathrm{~g}$ \\
\hline & & Honey & $15 \mathrm{~g}$ \\
\hline & & Jam & $15 \mathrm{~g}$ \\
\hline & & Chocolate spread & $15 \mathrm{~g}$ \\
\hline & & Peanut butter & $30 \mathrm{~g}$ \\
\hline & & Syrups & $15 \mathrm{~g}$ \\
\hline \multirow[t]{2}{*}{9} & Yogurt & Yogurt & $175 \mathrm{~g}$ \\
\hline & & Flavored yogurt & $175 \mathrm{~g}$ \\
\hline \multirow[t]{2}{*}{10} & Mixed dishes & $\begin{array}{l}\text { Mixed dishes: pizza or } \\
\text { burger, all varieties }\end{array}$ & $140 \mathrm{~g}$ \\
\hline & & $\begin{array}{l}\text { Mixed dishes: Chinese, all } \\
\text { varieties }\end{array}$ & $140 \mathrm{~g}$ \\
\hline \multirow[t]{3}{*}{11} & Condiments and & Ketchup & $15 \mathrm{~g}$ \\
\hline & sauces & $\begin{array}{l}\text { Salad dressing: ranch, blue } \\
\text { cheese, and Italian }\end{array}$ & $30 \mathrm{~g}$ \\
\hline & & $\begin{array}{l}\text { Salad dressing: french, } \\
\mathrm{BBQ} \text {, and thousand island }\end{array}$ & $30 \mathrm{~g}$ \\
\hline 12 & Fruits & Canned fruits & $125 \mathrm{~g}$ \\
\hline
\end{tabular}




\section{Statistical Analysis}

Descriptive data for continuous variables shown in this study are mean \pm standard deviation (SD) or median [interquartile range (IQR)], while data for categorical variables are presented as frequency [percentage (\%)]. To validate the semi-quantitative FFQ, Spearman's correlation test was conducted to (1) Investigate the correlation between free FS assessed by FFQ and the reference method (24-h dietary recall); (2) to assess the reproducibility of the newly developed FFQ. Children were grouped into quartiles (same quartile, adjacent quartile, and opposite quartile) to test the agreement in ranking children according to estimated FS intake from both methods. Weighted Kappa statistics was used to assess the interrater reliability across the two dietary collection tools. To evaluate internal consistency of items included in the FFQ, Cronbach's alpha test was used. To assess internal consistency of items included in the FFQ, frequency of consumption of each item was coded between 0 to 8 . Responses were coded following the criteria: 0 if the response was less than once a month; 1 if the response was 1-3 times a month; 2 if the response was once a week; 3 if the response was 2-4 times a week; 4 if the response was 5-6 times a week; 5 if the response was once a day; 6 if the response was 2-3 times a day; 7 if response was $4-5$ times a day; 8 if response was 6 or more a day. The Bland-Altman plot was used to assess the difference in FS intake reported by 24-h dietary recall and the FFQ compared to the mean intake of the two measures. However, a significant difference was observed between the two methods; therefore Bland-Altman plot was not constructed (24). Paired $t$-test was used to compare the difference between intake of FS assessed by the FFQ and 24-h dietary recall. All tests used in this study were two-tailed with a significant level of 0.05. Statistical Package for Social Sciences (SPSS) version 20 was used to analyze data presented in this study (SPSS, Inc., Chicago, IL, USA).

\section{RESULTS}

The final analysis included data of 424 children after excluding children with chronic diseases and allergies $(6.68 \%, n=36)$ and children with incomplete dietary data $(14.7 \%, n=79)$. Characteristics of children and mothers included in this study are described in Table 2. Proportion of children aged 6-7 years was $34.0 \%$ ( $n=144)$; children aged $8-9$ years was $29.7 \%(n$ $=144)$; and children aged $10-12$ years was $36.3 \%(n=154)$. Approximately half of the study sample were girls $(n=214)$. Twenty-five percent of mothers had a high-school degree or less $(n=105)$. Fifty-four percent of mothers reported family income of 10,000 Saudi Riyals (SR) per month or more.

Median intake FS assessed by FFQ was 83.5 g/day (58.0114 ), while median intake FS assessed by 24 -h dietary recall was $42.0 \mathrm{~g} /$ day (26.0-60). Mean intake of FS assessed by the FFQ was significantly higher than mean intake of FS assessed by the 24 -h dietary recall $(94.5 \pm 52.8 \mathrm{~g} /$ day vs. $44.9 \pm 25.7 \mathrm{~g} /$ day, respectively, $p<0.05$ ) (see Table 3 ). The correlation between total FS assessed by the FFQ and the 24-h dietary recall was positively low $\left(r_{\mathrm{s}}=0.30, p<0.001\right)$.
TABLE 2 | Characteristics of the study sample $(n=424)$.

\begin{tabular}{|c|c|c|}
\hline & $n$ & $\%$ \\
\hline \multicolumn{3}{|l|}{ Age group } \\
\hline $6-7$ years & 144 & 34.0 \\
\hline $8-9$ years & 126 & 29.7 \\
\hline $10-12$ years & 154 & 36.3 \\
\hline \multicolumn{3}{|l|}{ Sex } \\
\hline Boys & 210 & 49.5 \\
\hline Girls & 214 & 50.5 \\
\hline \multicolumn{3}{|c|}{ Maternal age group } \\
\hline$<30$ years & 76 & 17.9 \\
\hline 30-40 years & 239 & 56.4 \\
\hline$>40$ years & 109 & 25.7 \\
\hline \multicolumn{3}{|c|}{ Maternal education level } \\
\hline$\leq$ High-school & 105 & 24.8 \\
\hline University & 270 & 63.7 \\
\hline Postgraduate & 49 & 11.6 \\
\hline \multicolumn{3}{|c|}{ Family monthly income } \\
\hline$<$ SR 4,000 & 29 & 6.80 \\
\hline SR 4,000-10,000 & 166 & 39.2 \\
\hline$>$ SR 10,000 & 229 & 54.0 \\
\hline
\end{tabular}

Agreement of quartiles between FFQ and 24-h dietary recall is shown in Table 4. Data indicated that $73.6 \%(n=312)$ of children were classified into the same and adjacent quartiles, whereas $26.4 \%(n=112)$ of children were misclassified. The interrater reliability for the FFQ and the 24 -h recalls was found to be $\kappa=0.21$ (95\% confidence interval, 0.14-0.28), $p<0.001$.

The value of Cronbach's alpha $(\alpha=0.74)$ suggests good reliability for the FFQ among the study sample. To assess test-retest reliability, Spearman's correlation between FS intake from initial FFQ and repeated FFQ indicated positively high correlation $\left(r_{\mathrm{s}}=0.82, p<0.001\right)$.

\section{DISCUSSION}

Mean intake of FS assessed by the FFQ was significantly higher than the mean intake of FS assessed by the 24-h dietary recall. Spearman's correlation between the intake of FS assessed by FFQ and 24-h dietary recall was low. The FFQ demonstrated good internal consistency and high level of test-retest reliability.

Mean intake of FS assessed by the FFQ was $110 \%$ higher than the mean intake of FS assessed by the 24-h dietary recall. Significant differences in mean FS intake obtained using the FFQ and the 24-h dietary recalls have been also reported previously, where higher estimates were generally obtained by the FFQ $(23,25)$. Several possible explanations could attribute to the variation between the data obtained from these two dietary collection methods; One is the multiple food items included in the FFQ, which could help in eliminating memory bias and assist in obtaining more accurate estimates of FS intake $(23,26)$. In fact, foods that are high in FS are most likely consumed between 
TABLE 3 | Mean difference and Spearman's correlation for free sugar intake obtained using food frequency questionnaire and 24-h dietary recall ( $n=424)$.

\begin{tabular}{|c|c|c|c|c|c|}
\hline Free sugar (g) & FFQ mean \pm SD & 24-h dietary recall mean \pm SD & Mean difference & $\%$ of mean difference & Spearman correlation \\
\hline All children & $94.5 \pm 52.8$ & $44.9 \pm 25.7$ & $49.6 \pm 51.3^{a}$ & $110 \pm 114$ & $0.30^{a}$ \\
\hline Boys $(n=210)$ & $97.7 \pm 54.9$ & $45.7 \pm 26.6$ & $52.0 \pm 53.4^{a}$ & $114 \pm 117$ & $0.30^{\mathrm{a}}$ \\
\hline Girls $(n=214)$ & $91.4 \pm 50.6$ & $44.1 \pm 24.8$ & $47.3 \pm 49.2^{\mathrm{a}}$ & $107 \pm 112$ & $0.29^{a}$ \\
\hline
\end{tabular}

a Significant difference was denoted at confidence level of $95 \%$.

Mean difference $=$ Mean FFQ - Mean 24-h dietary recall.

Percentage of mean difference $=\frac{\text { Mean } F F Q-\text { Mean } 24-h \text { dietary recall }}{\text { Mean } 24-h \text { dietary recall }} \times 100$.

TABLE 4 | Agreement of quartiles for free sugar intake assessed by the food frequency questionnaire and 24-h dietary recalls ( $n=424)$.

\begin{tabular}{|c|c|c|c|c|c|}
\hline & \multicolumn{5}{|c|}{ Agreement of quartiles between FFQ and 24-h dietary recall } \\
\hline & Same quartile & Adjacent quartile & Opposite quartile & Weighted Kappa & $95 \%$ confidence interval \\
\hline All children & $147(34.7)$ & 165 (38.9) & $112(26.4)$ & $0.21^{a}$ & $0.14-0.28$ \\
\hline Boys $(n=210)$ & 67 (31.9) & $89(42.4)$ & $54(25.7)$ & $0.20^{a}$ & $0.10-0.29$ \\
\hline Girls $(n=214)$ & $80(37.4)$ & $76(35.5)$ & $58(27.1)$ & $0.23^{a}$ & $0.13-0.33$ \\
\hline
\end{tabular}

Numbers presented in the table are frequencies (\%). a Significant difference was denoted at confidence level of 95\%.

meals, of which can be more difficult to recall compared to foods consumed in regular meals. Besides, underreporting of emptycaloric foods have been previously documented $(27,28)$. To properly estimate the habitual intake of a particular nutrient, the number of 24-h dietary recalls should be determined based on the variation of nutrient of interest. Otherwise, intake of the nutrient might not accurately reflect its habitual intake. On the other hand, FFQ can be food/nutrient specific, require less resources, and provide data concerning habitual intake of food/nutrient.

Our data collected using FFQ indicated that children consume $94.5 \pm 52.8 \mathrm{~g}$ of FS per day, estimated approximately as 19 teaspoons. This excessive intake of FS among Saudi children exceeded the AHA by more than three times. In fact, the WHO and other health organizations strongly recommended assessing and monitoring consumption FS intake among populations. However, to our knowledge, studies that evaluated FS intake among children are limited. Several studies suggested high intake of sugary foods and drinks among Saudi children and reported positive correlations with body mass index and waist circumference in these children $(29,30)$. Given the high prevalence of obesity and associated poor dietary choices/intake among Saudi children $(7,29,30)$, a close attention should be paid to dietary intake of these children and associated factors. This is particularly important for children as the current evidence indicates that dietary behaviors of children may last to adulthood (18).

In epidemiologic studies, the usefulness of the FFQ can be considered superior to the 24-h dietary recalls due to its ability to quantify individuals into categories of nutrient intake (31). The FFQ developed in this study demonstrated a significant but slight agreement between the two dietary tools (32), with $34.7 \%$ being correctly classified into the same quartile and $38.9 \%$ into the adjacent quartile. Spearman correlation between total FS assessed by the FFQ and the 24-h dietary recall indicated a significantly low positive correlation. A review of 227 FFQ validation studies also showed limited correlations between data of the FFQ and the reference methods, ranging between 0.39 and 0.55 (33). The low correlations observed could be explained by the fact that the FFQs typically aim to assess the habitual/usual intake of certain nutrients, reflecting the consumption over a longer duration compared to data obtained from 24-h dietary recalls. The high variability in misreporting dietary data across individuals has possibly attributed to the low correlation between the two dietary assessment tools. The 24-h dietary recall method can be more biased due to the problem of underreporting, specifically FS foods, most likely because food high in FS are consumed between meals $(27,28)$, whereas the FFQ allows to allocate these foods using direct questions for better estimation of FS intake.

The FFQ developed in this study features with its ability to estimate the habitual intake of FS among Saudi children. The FFQ included culturally specific food items that are commonly consumed by Saudi children. For future research, energy drinks may be eliminated from the FFQ item list due to the very limited consumption among Saudi children, as opposed to American children who were reported to consume energy drinks frequently (17).

This is the first study in Saudi Arabia and the Middle East to develop and validate a tool that specifically assesses the habitual intake of free sugar. The FFQ can further provide data concerning food sources of FS and form of FS (liquid vs. solid). Utilization of the FFQ can offer the opportunity to investigate the associations between FS intake and related diseases. However, validating the FFQ among the different age groups is warranted. Limitations of this study include that the developed FFQ provides dietary data pertaining FS exclusively, whereas information on energy intake and the intake of other nutrients cannot be determined. In addition, the FFQ included food items that contain quantities of 
FS only. Thus, percentage of FS from total energy intake cannot be calculated.

In conclusion, the newly developed FFQ can be used to estimate the habitual FS intake among children in Saudi Arabia. Future direction may include investigations on possible predictors of excessive FS consumption and relevant food sources. Additionally, validation of the FFQ among different age groups would provide an insight into the relationship between habitual intake of FS and non-communicable diseases.

\section{DATA AVAILABILITY STATEMENT}

The raw data supporting the conclusions of this article will be made available by the authors, without undue reservation.

\section{ETHICS STATEMENT}

The studies involving human participants were reviewed and approved by the Ethical Committee of the College of Applied Medical Sciences, Taibah University (certificate\#

\section{REFERENCES}

1. Muth ND, Dietz WH, Magge SN, Johnson RK, Bolling CF, Armstrong SC, et al. Public policies to reduce sugary drink consumption in children and adolescents. Pediatrics. (2019) 143:e20190282. doi: 10.1542/peds.2019-0282

2. Jawaldeh A Al, Mallah C, Obeid O. Regional policies on sugar intake reduction at population levels to address obesity in the eastern mediterranean. JSM Nutr Disord. (2018) 2:1006. doi: 10.6084/m9.figshare.8247836.v1

3. Te Morenga L, Mallard S, Mann J. Dietary sugars and body weight: systematic review and meta-analyses of randomised controlled trials and cohort studies. BMJ. (2013) 346:e7492. doi: 10.1136/bmj.e7492

4. Moynihan P. Sugars and dental caries: evidence for setting a recommended threshold for intake. Adv Nutr. (2016) 7:149-56. doi: 10.3945/an.115. 009365

5. Wang JW, Shang L, Light K, O'Loughlin J, Paradis G, Gray-Donald K. Associations between added sugar (solid vs. liquid) intakes, diet quality, and adiposity indicators in Canadian children. Appl Physiol Nutr Metab. (2015) 40:835-41. doi: 10.1139/apnm-2014-0447

6. Mumena WA, Alamri AA, Mahrous AA, Alharbi BM, Almohaimeed JS, Hakeem MI, et al. Knowledge, attitudes, and practices toward added sugar consumption among female undergraduate students in Madinah, Saudi Arabia: a cross-sectional study. Nutrition. (2020) 7980:110936. doi: 10.1016/j.nut.2020.110936

7. Mumena W. Consumption of free sugar predicts nutrient intake of Saudi children. Front Nutr. (2021) 8:782853. doi: 10.3389/fnut.2021.782853

8. Te Morenga LA, Howatson AJ, Jones RM, Mann J. Dietary sugars and cardiometabolic risk: systematic review and meta-analyses of randomized controlled trials of the effects on blood pressure and lipids. Am J Clin Nutr. (2014) 100:65-79. doi: 10.3945/ajcn.113.081521

9. Yang Q, Zhang Z, Gregg EW, Flanders WD, Merritt R, Hu FB. Added sugar intake and cardiovascular diseases mortality among us adults. JAMA Intern Med. (2014) 174:516-24. doi: 10.1001/jamainternmed.2013.13563

10. World Health Organization. Guideline: Sugars Intake for Adults and Children. Geneva: World Health Organization (2015).

11. Mela DJ, Woolner EM. Perspective: total, added, or free? what kind of sugars should we be talking about? Adv Nutr. (2018) 9:63-9. doi: 10.1093/advances/nmx020

12. Vos MB, Kaar JL, Welsh JA, Van Horn L V., Feig DI, Anderson CAM, et al. Added sugars and cardiovascular disease risk in children: a scientific statement from the American heart association. Circulation. (2017) 135:e1017-34. doi: 10.1161/CIR.0000000000000439
2020/55/202/CLN). Written informed consent to participate in this study was provided by the participants' legal guardian/next of kin.

\section{AUTHOR CONTRIBUTIONS}

WM and HK conceived the study, developed the tool, conducted the analyses, interpreted the results, and wrote the paper. All authors critically reviewed the manuscript and approved the final version submitted for publication.

\section{ACKNOWLEDGMENTS}

Thanks are due to all members of the Dietary Intake of Saudis project for their contribution to data collection. Special thanks to Ms. Fatima Abdulhakeem and Ms. Najwan Jannadi from the Virtual Dietary Assessment Lab for their support during dietary data entry. Additional thanks to all mothers and children who participated in this study.
13. Ministry of Health Saudi Arabia. Healthy Food Guidelines for Health Practitioners. (2020). Available online at: https://www.moh.gov.sa/ Ministry/About/Health\%20Policies/Healthy-Food-Guidelines-for-HealthPractitioners.pdf

14. Alsubaie ASR. Consumption and correlates of sweet foods, carbonated beverages, and energy drinks among primary school children in Saudi Arabia. Saudi Med J. (2017) 38:1045-50. doi: 10.15537/smj.2017.10.19849

15. Otaibi $\mathrm{HH}$ Al. Sugar sweetened beverages consumption behavior and knowledge among university students in Saudi Arabia perspective. J Econ Bus Manag. (2017) 5:173-6. doi: 10.18178/joebm.2017.5.4.507

16. Islam MA, Al-karasneh AF, Hussain A Bin, Muhanna A, Albuhulayqah $\mathrm{T}$, Naqvi AA, et al. Assessment of beverage consumption by young adults in Saudi Arabia. Saudi Pharm J. (2020) 28:1635-47. doi: 10.1016/j.jsps.2020.10.010

17. Bailey RL, Fulgoni VL, Cowan AE, Gaine PC. Sources of added sugars in young children, adolescents, and adults with low and high intakes of added sugars. Nutrients. (2018) 10:102. doi: 10.3390/nu10010102

18. Movassagh EZ, Baxter-Jones ADG, Kontulainen S, Whiting SJ, Vatanparast H. Tracking dietary patterns over 20 years from childhood through adolescence into young adulthood: the saskatchewan pediatric bone mineral accrual study. Nutrients. (2017) 9:990. doi: 10.3390/nu9090990

19. Bestle SMS, Christensen BJ, Trolle E, Biltoft-Jensen AP, Matthiessen J, Gibbons SJ, et al. Reducing young schoolchildren's intake of sugar-rich food and drinks: study protocol and intervention design for "are you too sweet?" a multicomponent 3.5-month cluster randomised familybased intervention study. Int J Environ Res Public Health. (2020) 17:9580. doi: 10.3390/ijerph17249580

20. Fisher JO, Serrano EL, Foster GD, Hart CN, Davey A, Bruton YP, et al. Efficacy of a food parenting intervention for mothers with low income to reduce preschooler's solid fat and added sugar intakes: a randomized controlled trial. Int J Behav Nutr Phys Act. (2019) 16:6. doi: 10.1186/s12966-0180764-3

21. Rahman AA, Jomaa L, Kahale LA, Adair P, Pine C. Effectiveness of behavioral interventions to reduce the intake of sugar-sweetened beverages in children and adolescents: a systematic review and meta-analysis. Nutr Rev. (2018) 76:88-107. doi: 10.1093/nutrit/nux061

22. Hulley S, Cummings S, Browner W. Designing Clinical Research. 4th ed. Philadelphia: Wolters Kluwer (2015).

23. Nik Shanita S, Norimah N, Abu Hanifah S. Development and validation of a food frequency questionnaire (FFQ) for assessing sugar consumption among adults in Klang Valley, Malaysia. Malays J Nutr. (2012) 18:283-93. 
24. Giavarina D. Understanding bland altman analysis. Biochem Medica. (2015) 25:141-51. doi: 10.11613/BM.2015.015

25. Subar AF, Thompson FE, Kipnis V, Midthune D, Hurwitz P, McNutt S, et al. Comparative validation of the block, willett, and national cancer institute food frequency questionnaires: the eating at america's table study. Am J Epidemiol. (2001) 154:1089-99. doi: 10.1093/aje/154.12.1089

26. Chee WSS, Suriah AR, Zaitun Y, Chan SP, Yap SL, Chan YM. Dietary calcium intake in postmenopausal Malaysian women: comparison between the food frequency questionnaire and three-day food records. Asia Pac J Clin Nutr. (2002) 11:142-6. doi: 10.1046/j.1440-6047.2002.00 276.x

27. Poppitt SD, Swann D, Black AE, Prentice AM. Assessment of selective under-reporting of food intake by both obese and non-obese women in a metabolic facility. Int J Obes. (1998) 22:303-11. doi: 10.1038/sj.ijo.080 0584

28. King BM, Ivester AN, Burgess PD, Shappell KM, Coleman KL, Cespedes VM, et al. Adults with obesity underreport high-calorie foods in the home. Heal Behav Policy Rev. (2016) 3:439-43. doi: 10.14485/HBPR.3.5.4

29. Collison KS, Zaidi MZ, Subhani SN, Al-Rubeaan K, Shoukri M, Al-Mohanna FA. Sugar-sweetened carbonated beverage consumption correlates with BMI, waist circumference, and poor dietary choices in school children. BMC Public Health. (2010) 10:234. doi: 10.1186/1471-2458-10-234

30. Amin TT, Al-Sultan AI, Ali A. Overweight and obesity and their relation to dietary habits and socio-demographic characteristics among male primary school children in Al-Hassa, Kingdom of Saudi Arabia. Eur J Nutr. (2008) 47:310-8. doi: 10.1007/s00394-008-0727-6
31. Cade J, Thompson R, Burley V, Warm D. Development, validation and utilisation of food-frequency questionnaires - a review. Public Health Nutr. (2002) 5:567-87. doi: 10.1079/PHN2001318

32. Landis JR, Koch GG. The measurement of observer agreement for categorical data. Biometrics. (1977) 33:159-74. doi: 10.2307/2529310

33. Cade JE, Burley VJ, Warm DL, Thompson RL, Margetts BM. Food-frequency questionnaires: a review of their design, validation and utilisation. Nutr Res Rev. (2004) 17:5-22. doi: 10.1079/NRR200370

Conflict of Interest: The authors declare that the research was conducted in the absence of any commercial or financial relationships that could be construed as a potential conflict of interest.

Publisher's Note: All claims expressed in this article are solely those of the authors and do not necessarily represent those of their affiliated organizations, or those of the publisher, the editors and the reviewers. Any product that may be evaluated in this article, or claim that may be made by its manufacturer, is not guaranteed or endorsed by the publisher.

Copyright (C) 2022 Mumena and Kutbi. This is an open-access article distributed under the terms of the Creative Commons Attribution License (CC BY). The use, distribution or reproduction in other forums is permitted, provided the original author(s) and the copyright owner(s) are credited and that the original publication in this journal is cited, in accordance with accepted academic practice. No use, distribution or reproduction is permitted which does not comply with these terms. 